\title{
Correction to: Design and Development of a Variable Configuration Delivery Robot Platform
}

\section{Mingeuk Kim ${ }^{1}$ - Dongil $\mathrm{Choi}^{2}$ (])}

Published online: 29 November 2019

(c) Korean Society for Precision Engineering 2019

\section{Correction to: \\ International Journal of Precision Engineering and Manufacturing (2019) 20:1757-1765 \\ https://doi.org/10.1007/s12541-019-00188-9}

The original version of this article unfortunately contains a mistake. The acknowledgement section of the above article should read as follows:

Acknowledgements This research was supported by the Civil-Military Technology Program of ICMTC (19-CM-GU-02), the Basic Research Project of KIMM (NK220C) and 2018 Research Fund of Myongji University.
Publisher's Note Springer Nature remains neutral with regard to jurisdictional claims in published maps and institutional affiliations.

The original article can be found online at https://doi.org/10.1007/ s12541-019-00188-9.

Dongil Choi

dongilc@mju.ac.kr

1 Korea Institute of Machinery and Materials, 156

Gajeongbuk-Ro, Yuseong-Gu, Daejeon 34103, South Korea

2 Department of Mechanical Engineering, Myongji University, 116 Myongji-ro, Cheoin-gu, Yongin-si, Gyeonggi-Do 17058, South Korea 